\title{
Step-by-step evaluation and treatment of shoulder dislocation
}

\author{
Tailor management decisions by taking into account \\ the patient's age, the direction of instability, functional \\ demands, risk of recurrence, and associated injuries.
}

\section{PRACTICE \\ RECOMMENDATIONS}

> Refer first-time dislocation in patients younger than 20 years or who have a displaced fracture to an orthopedic surgeon. (A)

> Order magnetic resonance imaging (MRI) for all patients with a suspected rotator cufftear. A

> Send patients with weakness of the rotator cuff-but no tear on MRI-for evaluation by electromyography and nerve-conduction studies. A

Strength of recommendation (SOR)

A Good-quality patient-oriented evidence

B Inconsistent or limited-quality patient-oriented evidence

C Consensus, usual practice, opinion, disease-oriented evidence, case series
7 he architecture of the glenohumeral joint makes it the most common large joint to become dislocated, accounting for approximately $45 \%$ of all dislocations. Anterior dislocation constitutes more than $95 \%$ of glenohumeral joint dislocations; posterior dislocation, only $2 \%$ to $5 \% .^{1,2}$

For the family physician, determining appropriate follow-up after emergent reduction depends on several distinct variables, which we review here; subsequent treatment might involve, as we outline, physical therapy, immobilization, surgical intervention, or a combination of several modalities. Treatment decisions can make the difference between successful rehabilitation and potential disability, particularly in typically young and active patients.

\section{Numerous mechanisms of injury}

I Anterior shoulder dislocations typically occur with the affected shoulder in a position of abduction and external rotation; $90 \%$ of patients are 21 to 30 years of age, and men are affected 3 times more often than women. ${ }^{2}$ Unsurprisingly, athletes are affected most frequently, with the common sportsrelated mechanism of injury being either sudden pressure exerted on the abducted and externally rotated arm or a fall onto an outstretched hand with the arm elevated. Repetitive microtrauma from such sports as swimming, baseball, and volleyball can also lead to instability.

I Bankart lesion. This tear of the anterior or inferior section of the labrum is the most characteristic lesion noted in anterior dislocations, found in $73 \%$ of first-time dislocations and $100 \%$ of recurrent dislocations. ${ }^{3,4}$

I Hills-Sachs lesion is often associated with a Bankart lesion. The Hills-Sachs lesion is an impaction fracture of the posterolateral aspect of the humeral head resulting from its displacement over the anterior lip of the glenoid. Hill-Sachs lesions are seen in $71 \%$ of first-time and recurrent dislocations. ${ }^{3}$
Nata Parnes, MD; Jeff Perrine, FNP-C; Kenneth J. Fish, DO, FAAFP

Carthage Area Hospital (Dr. Parnes and Mr. Perrine) and Family Practice Associates (Dr. Fish), Carthage, NY, and ClaxtonHepburn Medical Center, Ogdensburg, NY (Dr. Parnes)

Dnparnes@cahny.org

The authors reported no potential conflict of interest relevant to this article.

doi: $0.12788 /$ jfp.0279 


\section{FIGURE}

\section{Reduction of anterior shoulder dislocation using the Milch technique}

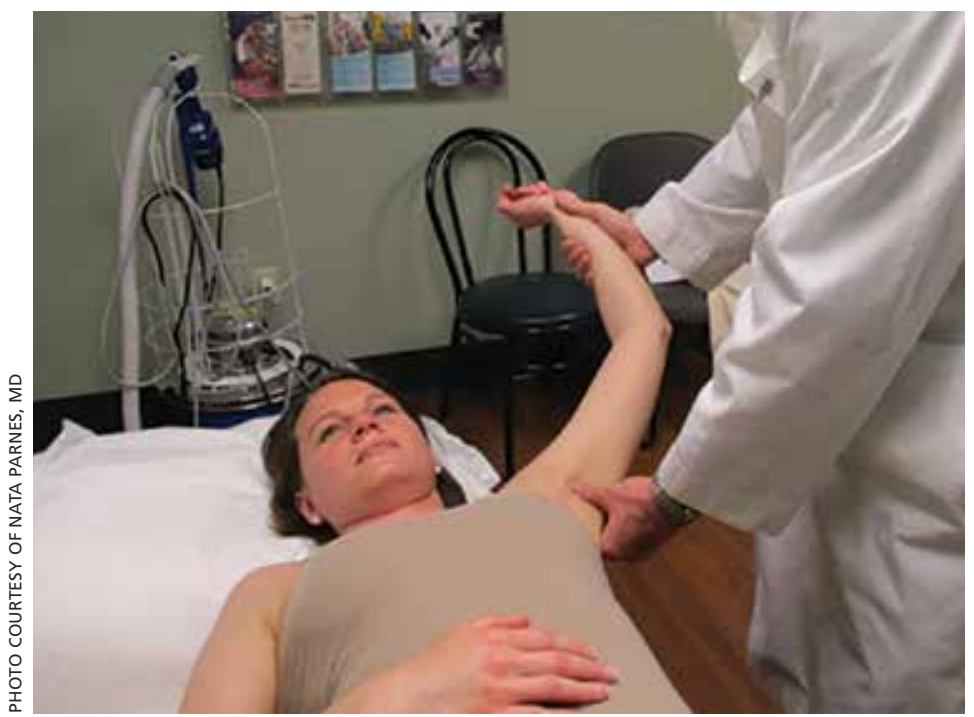

With the patient supine, apply gentle but firm downward traction to the humerus at the elbow while the affected arm is in abduction and external rotation. You can manipulate the humeral head at that point by placing a thumb in the patient's axilla. be reduced as soon as possible to minimize neurovascular injury and patient discomfort. (Typically, but not always, this is done in the emergency department.) It is crucial to have effective muscle relaxation before any attempt at reduction, to minimize the risk of iatrogenic injury to bone, cartilage, tendons, and neurovascular structures.

Muscle relaxation can be facilitated with intravenous midazolam or other agents, as specified by institutional protocol. Intraarticular lidocaine injection or intravenous fentanyl is often utilized in conjunction with the sedating agent to reduce pain and further accommodate relaxation.

- Anterior reduction. Any one of several techniques can be used to perform emergent reduction of anterior shoulder dislocations, all of which have demonstrated success. The Milch technique is among the least traumatic for effective reduction. ${ }^{6}$ In this technique (FIGURE 1), the patient is supine; gentle but firm downward traction is applied to the humerus at the elbow of the affected arm while the arm is in abduction and external rotation. The provider can manipulate the humeral head at that point by placing a thumb in the patient's axilla; the arm can also be further internally rotated and adducted until reduction is achieved.

I Posterior reduction of a dislocation is performed while the patient is supine, with the body stabilized. Traction is applied on the adducted and internally rotated arm in conjunction with direct pressure on the posterior aspect of the humeral head (FIGURE 2).

I Follow-up actions. Before discharging the patient after reduction of a dislocation, it is essential to:

- perform post-reduction evaluation of shoulder stability at different levels of abduction

- perform a thorough neurovascular assessment

- obtain an anteroposterior (AP) radiograph to ensure proper positioning of the glenohumeral joint.

The reduced shoulder should be immobilized in a sling. The discharge plan should include pain management for several days 
and a follow-up appointment in 5 to 8 days with the primary care $\operatorname{provider}^{2}$ (FIGURE 3).

\section{Follow-up evaluation by the primary care provider}

I History. Prior to the initial examination at follow-up, obtain a comprehensive history that includes the nature of the injury and the direction of force that was placed on the shoulder. Determine whether the shoulder was reduced spontaneously or required manual reduction in the field or an emergency department. Note any associated injury sustained concurrently and the presence (or absence) of neck pain, numbness, tingling, or weakness in the affected arm.

I Physical exam starts with thorough inspection of the affected shoulder, with comparison to the contralateral side, at rest and during shoulder motion. Palpation to reveal points of tenderness should include the anterior joint line, acromioclavicular joint, bicipital groove, subacromial space, acromion, and greater tuberosity.

Following inspection and palpation, assess active and passive range of motion in forward elevation, abduction, internal and external rotation at the side of the body, and internal and external rotation in shoulder abduction. Assessment might be limited by pain and apprehension, and should be performed within the patient's comfortable range of motion.

Once range of motion is determined, assess $^{7}$ :

- muscle power of the rotator cuff in abduction (for the supraspinatus muscle)

- resisted external rotation at the side of the body (the infraspinatus)

- resisted external rotation in abduction $>60^{\circ}$ (the teres minor)

- resisted internal rotation (the subscapularis).

\section{Specific tests for shoulder laxity and stability}

It is important during the primary care follow-up examination to differentiate true instability and shoulder hyperlaxity, particularly in young, flexible patients (TABLE). Many of these patients present with painless hyper-

\section{FIGURE 2}

\section{Reduction of posterior shoulder dislocation}

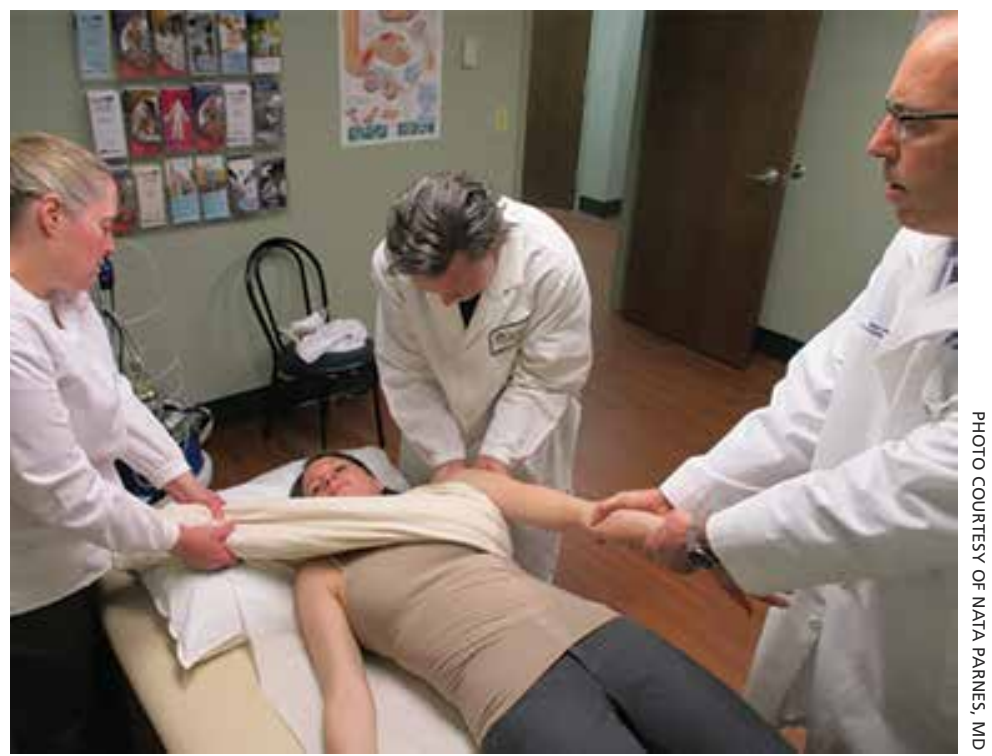

With the patient supine, the body is stabilized by Assistant 1 (at left). Apply traction on the adducted and internally rotated arm, in conjunction with direct pressure applied by Assistant 2 (at right) on the posterior aspect of the humeral head.

mobility of the shoulder without true injury to the labrum or ligamentous structures. It might appear to the patient, or to family, that the shoulder is subluxating; however, the humeral head returns to a centered position on the glenoid in a hypermobile state-typically, without pain. Actual shoulder instability is defined as loss of the ability of the humeral head to re-center, accompanied by painpathology that is frequently associated with damage to the capsulolabral complex.

I The load and shift test is used to assess anterior and posterior laxity. The patient is seated, and the forearm is allowed to rest on the thigh. Examination is performed using 1 hand to press anteriorly or posteriorly on the humeral head; the other hand is simultaneously positioned on the joint line to feel movement of the humeral head in relation to the glenoid (FIGURE 4).

I The apprehension test is a common maneuver used to assess anterior shoulder instability. It is performed by positioning the affected arm to $90^{\circ}$ external rotation and then elevating it to $90^{\circ}$ abduction. Although this maneuver can be performed with the patient 
Acute dislocation of the shoulder should be reduced as soon as possible to minimize neurovascular injury and patient discomfort.

\section{FIGURE 3}

\section{Anterior shoulder dislocation: Roadmap for emergent treatment}

Anterior shoulder dislocation is suspected based on the history

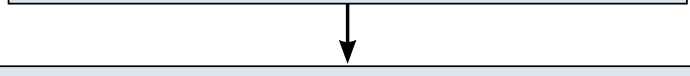

Findings on physical exam:

- Severe shoulder pain

- Inability to move the shoulder

- Arm is in slight abduction and external rotation

- The humeral head can be palpated below the coracoid process or the glenoid fossa is empty upon palpation (or both findings)

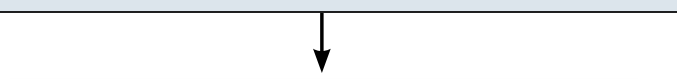

Perform a full neurovascular exam

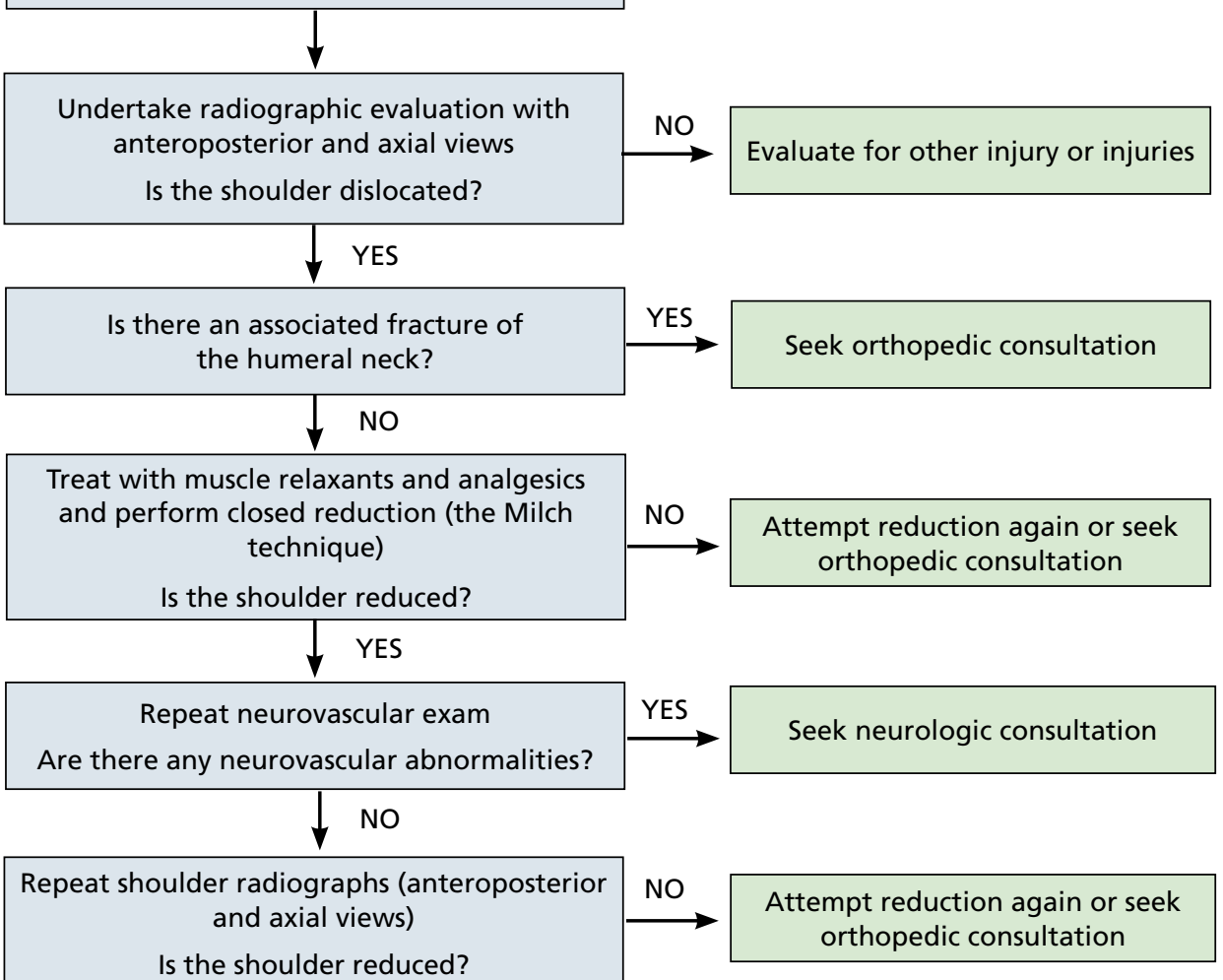

$$
\text { YES }
$$

Immobilize the shoulder in a sling

Is (are) there associated displaced fracture(s)? 
TABLE

Tests for assessing shoulder laxity and stability

\begin{tabular}{|c|c|c|c|}
\hline Test & Rationale & Technique & Positive result \\
\hline $\begin{array}{l}\text { Anterior load and shift } \\
\text { (FIGURE 4) }\end{array}$ & $\begin{array}{l}\text { Assessment of anterior } \\
\text { shoulder laxity }\end{array}$ & $\begin{array}{l}\text { With the patient seated, use } \\
\text { one hand to press anteriorly } \\
\text { on the humeral head of the } \\
\text { affected arm, with the other } \\
\text { hand positioned on the joint } \\
\text { line }\end{array}$ & $\begin{array}{l}\text { Anterior movement of the } \\
\text { humeral head in relation to } \\
\text { the glenoid }\end{array}$ \\
\hline Posterior load and shift & $\begin{array}{l}\text { Assessment of posterior } \\
\text { shoulder laxity }\end{array}$ & $\begin{array}{l}\text { With the patient seated, use } \\
\text { one hand to press posteriorly } \\
\text { on the humeral head of the } \\
\text { affected arm, with the other } \\
\text { hand positioned on the joint } \\
\text { line }\end{array}$ & $\begin{array}{l}\text { Posterior movement of the } \\
\text { humeral head in relation to } \\
\text { the glenoid }\end{array}$ \\
\hline Apprehension test (FIGURE 5) & $\begin{array}{l}\text { Assessment of anterior } \\
\text { shoulder instability }\end{array}$ & $\begin{array}{l}\text { With the patient upright } \\
\text { or supine, position the } \\
\text { affected arm in } 90^{\circ} \text { external } \\
\text { rotation and elevate it to } 90^{\circ} \\
\text { abduction }\end{array}$ & $\begin{array}{l}\text { Patient reports a sensation of } \\
\text { impending anterior instability }\end{array}$ \\
\hline Relocation test (FIGURE 6) & $\begin{array}{l}\text { Assessment of anterior } \\
\text { shoulder instability }\end{array}$ & $\begin{array}{l}\text { With the patient supine and } \\
\text { the affected arm positioned in } \\
90^{\circ} \text { external rotation and } 90^{\circ} \\
\text { abduction, apply a posteriorly } \\
\text { directed force on the humeral } \\
\text { head (ie, stabilizing it) }\end{array}$ & $\begin{array}{l}\text { Patient reports alleviation of } \\
\text { apprehension as long as the } \\
\text { examiner keeps stabilizing the } \\
\text { humeral head }\end{array}$ \\
\hline $\begin{array}{l}\text { Posterior apprehension test } \\
\text { (FIGURE 7) }\end{array}$ & $\begin{array}{l}\text { Assessment of posterior } \\
\text { shoulder instability }\end{array}$ & $\begin{array}{l}\text { With the patient supine and } \\
\text { the affected arm placed } \\
\text { in flexion, adduction, and } \\
\text { internal rotation, apply } \\
\text { posterior pressure }\end{array}$ & $\begin{array}{l}\text { Patient reports pain at the } \\
\text { posterior aspect of the } \\
\text { shoulder; clicking might be } \\
\text { noted }\end{array}$ \\
\hline Sulcus test (FIGURE 8) & $\begin{array}{l}\text { Assessment of multidirectional } \\
\text { instability }\end{array}$ & $\begin{array}{l}\text { With the patient seated } \\
\text { upright and arms resting at } \\
\text { their sides, perform a direct } \\
\text { downward pull of the affected } \\
\text { arm at elbow level }\end{array}$ & $\begin{array}{l}\text { A sulcus, or depression, is } \\
\text { noted at the lateral aspect of } \\
\text { the shoulder }\end{array}$ \\
\hline
\end{tabular}

upright, it is beneficial to have them supine, to more easily control the arm (FIGURE 5). A positive test is noted when the patient reports a sensation of impending instability (apprehension), rather than pain alone.

I Relocation test. When the apprehension test is positive, the supine position can be exploited to further perform the relocation test, in 2 stages (FIGURE 6):

- Apply a posteriorly directed force on the humeral head, which stabilizes the shoulder and typically alleviates symptoms.

- Release pressure quickly from the humeral head to assess recurrence of pain and apprehension as the humeral head snaps back against the anterior labrum.
Combined, apprehension and relocation tests to identify anterior shoulder instability have been shown to significantly improve specificity while maintaining sensitivity. ${ }^{8}$

The posterior apprehension test is used to assess posterior instability. The patient is supine; the affected arm is placed in flexion, adduction, and internal rotation; and posterior pressure is applied (FIGURE 7). A positive test is noted when pain is reported at the posterior aspect of the shoulder. Clicking might be noted as the humeral head dislocates rearward. ${ }^{1}$

- Sulcus sign. Multidirectional instability is elicited using the sulcus sign. While the patient is seated upright, arms resting at their sides, a direct downward pull at elbow 
FIGURE 4

\section{Load and shift test}

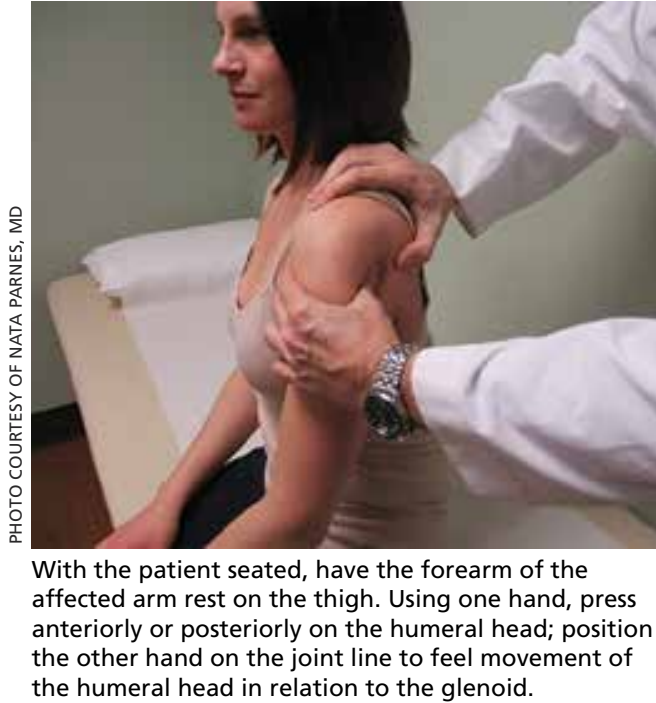

FIGURE 5

Apprehension test

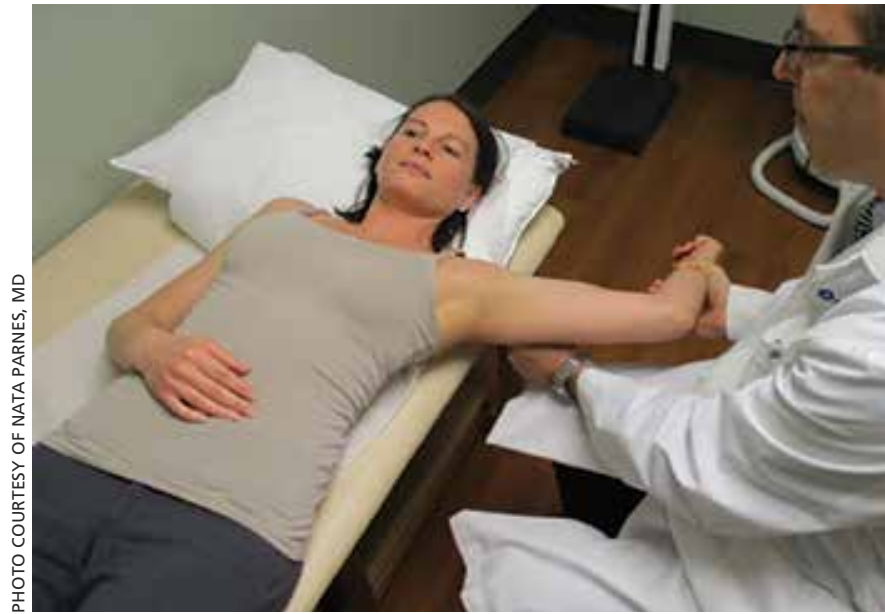

With the patient supine (for easier control of the affected arm), position the affected arm at $90^{\circ}$ external rotation and elevate it to $90^{\circ}$ abduction. The test is positive when the patient reports a sensation of impending instability (apprehension), rather than pain only.

\section{FIGURE 6}

\section{Relocation test}

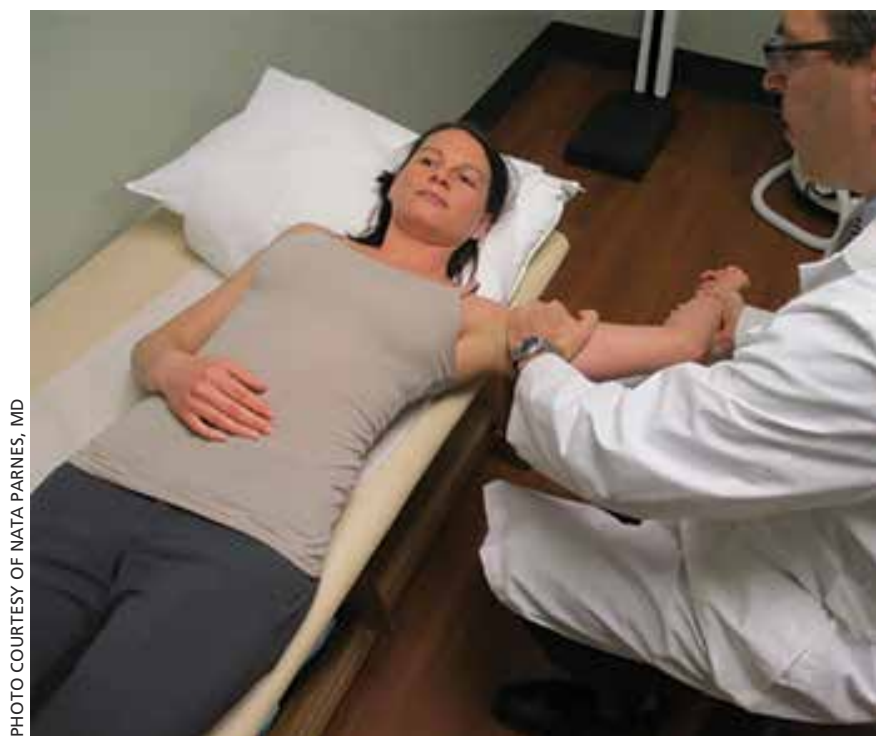

The test is performed in 2 stages: First, the examiner applies a posteriorly directed force on the humeral head, which stabilizes the shoulder and typically alleviates the symptoms. Second, pressure is released quickly from the humeral head to assess recurrence of pain and apprehension as the humeral head snaps back against the anterior labrum.

level will, when positive, reveal a depression (sulcus) at the lateral aspect of the affected shoulder as the humeral head translates inferiorly (FIGURE 8). A positive sulcus sign is documented in 3 grades, according to the amount of translation ${ }^{1}$.

- Grade I: $<1 \mathrm{~cm}$

- Grade II: $1-2 \mathrm{~cm}$

- Grade III: $>2 \mathrm{~cm}$.

I Neurovascular status should be verified at every physical evaluation, with motor and sensory function tested in the axillary, musculocutaneous, median, radial, and ulnar nerve distributions. If nerve injury is suspected, electromyography and nerve-conduction testing is indicated..$^{9-13}$ Vascular compromise is much less common but equally important to assess. ${ }^{11}$

\section{Use of imaging}

Post-reduction radiographs, including internal and external AP-and especially axillary-views are invaluable. Not only do they help to ensure reduction, but they also help to assess for fracture. A magnetic resonance imaging (MRI) arthrogram is the preferred imaging modality if a labral tear is suspected (FIGURE 9). Other concomitant shoulder injuries, such as subtle bone fracture, rotator cuff tear, and biceps pathology can also be reliably diagnosed with noncontrast MRI.

\section{Roadmap for treatment}

The rate of recurrence after a first anterior 
shoulder dislocation is strongly associated with a person's age and level of activity. Active patients younger than 20 years have a $92 \%$ to $96 \%$ recurrence rate ${ }^{14}$; patients 20 to 40 years, $25 \%$ to $48 \%$; and patients older than 40 years, $<10 \% .^{15}$

I Young, athletic patients who are treated nonoperatively are left at an unacceptably high risk of recurrence, leading to progressive damage to bony and soft-tissue structures. ${ }^{16,17}$ Surgical labral repair after a first-time anterior dislocation produced improved outcomes in terms of recurrent dislocation (7.9\%), compared to outcomes after nonsurgical treatment (52.9\%), ${ }^{14}$ and has been associated with a lower incidence of future glenohumeral osteoarthritis. ${ }^{18}$ For those reasons, we recommend referral to an orthopedic surgeon for all patients younger than 20 years who sustain an anterior shoulder dislocation.

I Patients older than 20 years who do not have concomitant shoulder injury, and who demonstrate full strength in abduction, external rotation, and internal rotation of the shoulder on clinical examination, have a low probability of associated rotator-cuff tear. They can be immobilized in a sling for 1 to 3 weeks, followed by a 6 to 12 -week regimen of physical therapy.

I Concomitant tear of the rotator cuff. Weakness on examination requires MRI or a magnetic resonance arthrogram for evaluation of associated rotator-cuff tear. A tear identified on MRI should be referred to an orthopedic surgeon because timely repair can be crucial to attaining best outcomes. Conservative treatment of traumatic full-tendon rotator-cuff tear is associated with poor results, progression in the size of the tear, and advancement of muscle atrophy. ${ }^{19,20}$ For patients younger than 40 years, arthroscopic rotator-cuff repair, with or without labral repair, produces excellent clinical outcomes, carries a low risk of complications, and results in a $>95 \%$ rate of return to a preoperative level of recreational and job activities. ${ }^{21}$

Patients who demonstrate weakness of the rotator-cuff muscles on examination, but who do not have a tear noted on MRI, should be evaluated by electromyography and nerve-conduction testing to assess nerve injury as an alternative cause of weakness. ${ }^{10,11}$

\section{FIGURE 7}

\section{Posterior apprehension test}

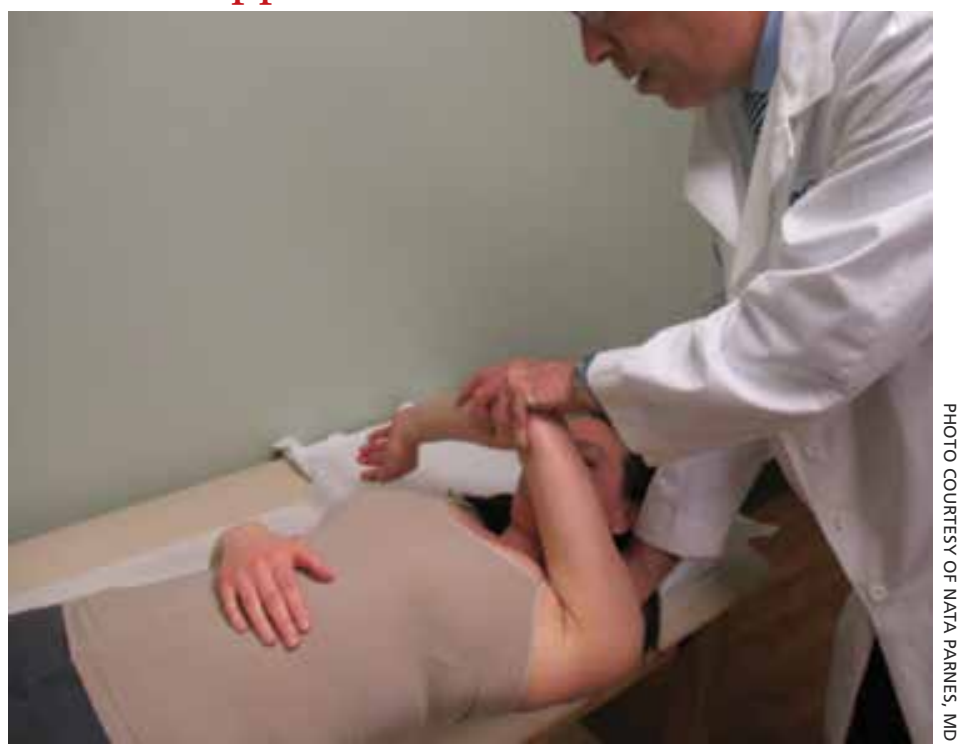

With the patient supine, place the affected arm in flexion, adduction, and internal rotation, and apply posterior pressure. The test is positive when pain is reported at the posterior aspect of the shoulder. Clicking might be noted as the humeral head dislocates rearward.

\section{FIGURE 8}

\section{Multidirectional instability revealed} by the sulcus sign

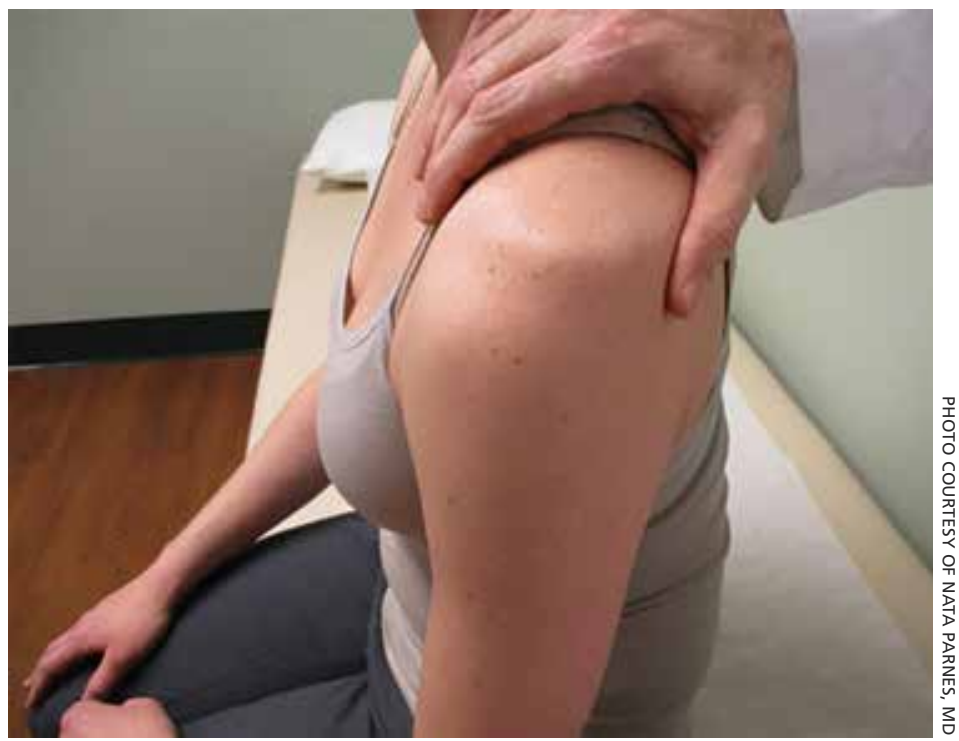

With the patient seated upright and arms resting at their sides, a direct downward pull at elbow level will, in the presence of multidirectional instability, reveal a sulcus, or depression, at the lateral aspect of the shoulder as the humeral head translates inferiorly.

If a neurologic deficit is found on nerveconduction testing, the patient should be referred for neurologic evaluation. ${ }^{10}$

CONTINUED 


\section{FIGURE 9}

\section{Bankart and Hill-Sachs lesions of the shoulder}

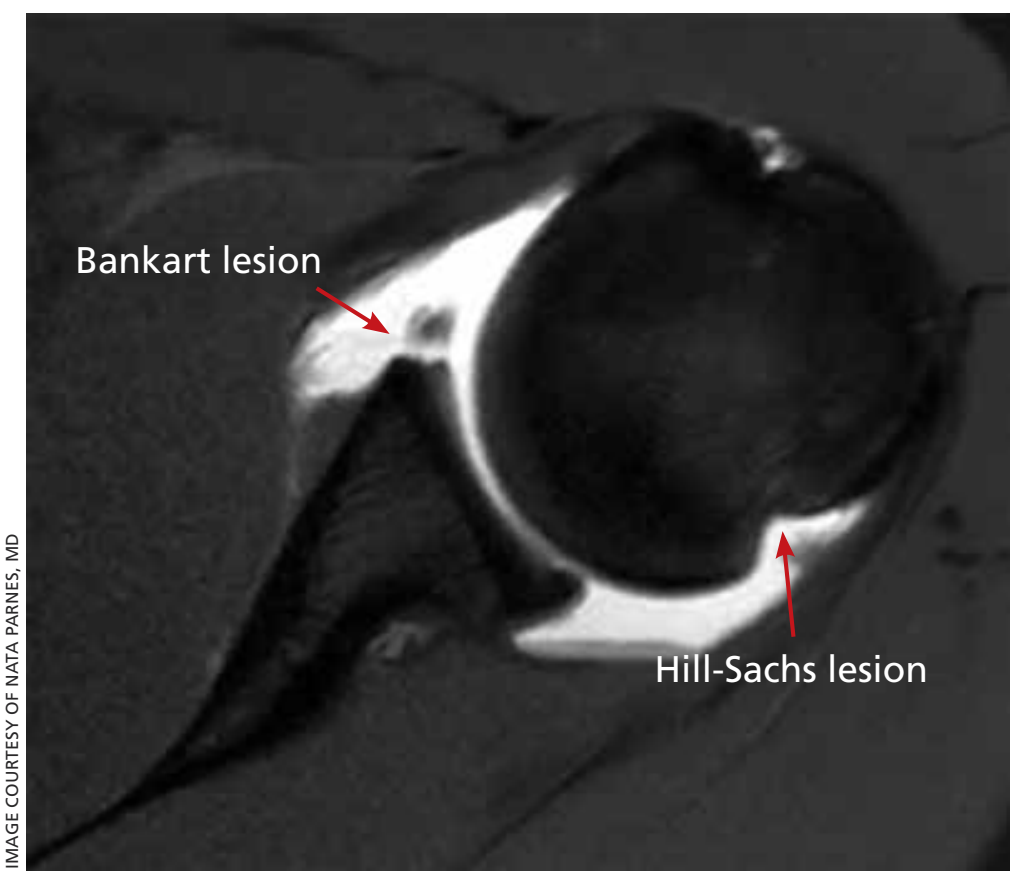

Axial T1 fat suppression magnetic resonance imaging arthrogram of the right shoulder demonstrates a typical Bankart lesion (anterior or inferior labral tear) and a Hill-Sachs lesion. meral head, greater tuberosity, or the glenoid itself. ${ }^{2}$ Clinical variables that predict a fracture associated with shoulder dislocation include ${ }^{23}$ :

- first episode of dislocation

- age $\geq 40$ years

- fall from higher than 1 flight of stairs

- fight or assault

- motor vehicle crash.

A computed tomography scan with 3-dimensional reconstruction can help characterize associated fracture accurately -including location, size, and displacement-and can play an important role in treatment planning and prognosis in these complicated injuries. Displaced fracture should be referred to an orthopedic surgeon. Nondisplaced fracture of the humeral head or greater tuberosity (FIGURE 11) poses less risk of complications and can be treated conservatively with 6 weeks in an arm sling, followed by physical therapy. ${ }^{24}$

\section{Summing up}

Management of shoulder dislocation must, first, be tailored to the individual and, second, account for several interactive factors-including age, direction of instability, functional demands, risk of recurrence, and associated injuries. In many patients, conservative treatment produces a favorable long-term outcome. Particularly in young, active patients with anterior shoulder instability, most surgeons consider open or arthroscopic reconstruction to be the treatment of choice. ${ }^{2,18}$

Pre-reduction and post-reduction imaging should be carefully examined for the presence of concomitant injury, which might change the preferred treatment modality appreciably.

Last, communication among emergency department providers, the primary care provider, orthopedist, radiologist, and neurologist is crucial for determining an appropriate patient-centered approach to initial and long-term management.

JFP

\section{CORRESPONDENCE}

Nata Parnes, MD, Carthage Area Hospital, 3 Bridge Street, Carthage, NY; nparnes@cahny.org 


\section{FIGURE 10}

\section{Anterior shoulder dislocation: Roadmap for treatment decisions}

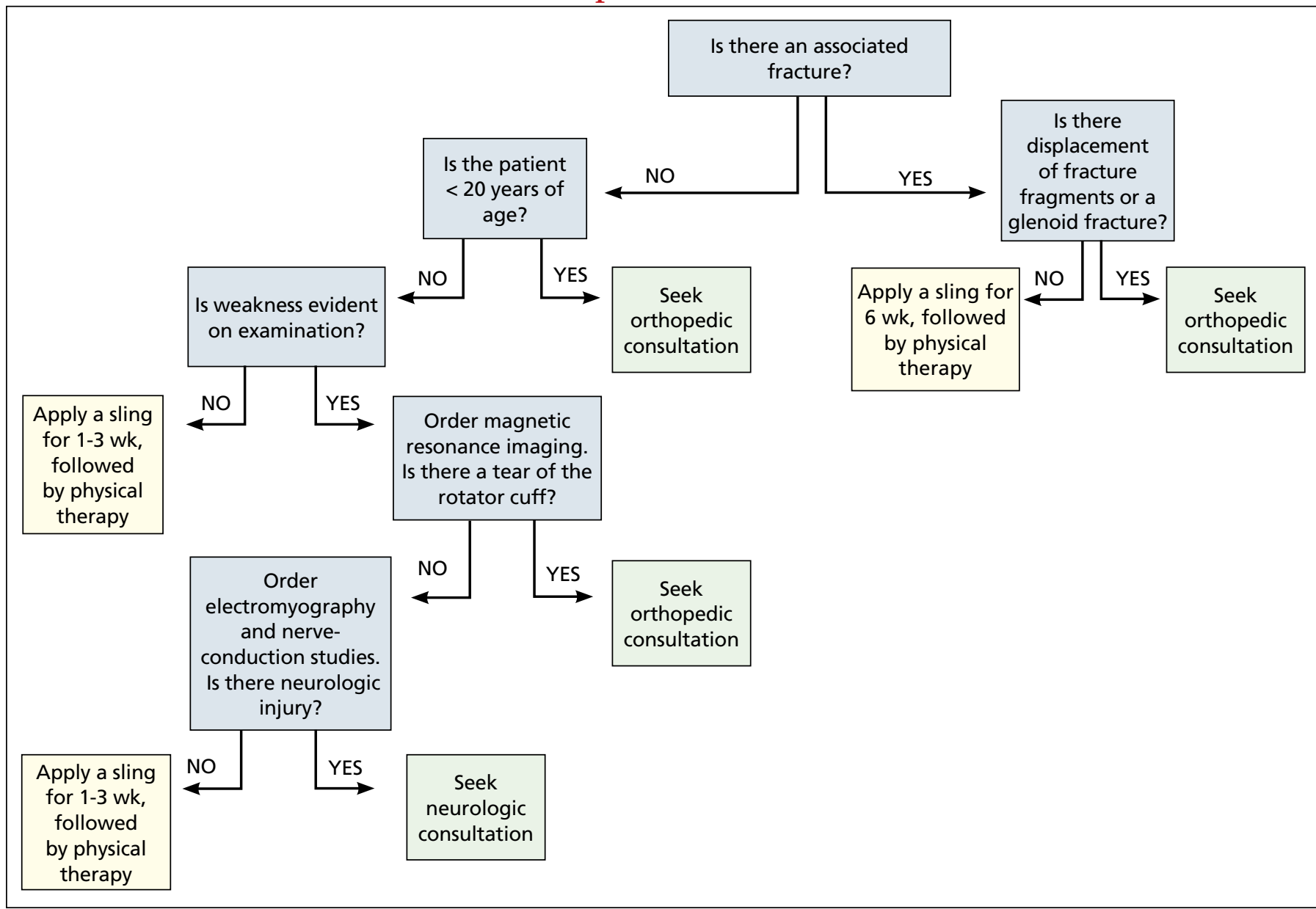

FIGURE 11

Nondisplaced fracture of the greater tuberosity

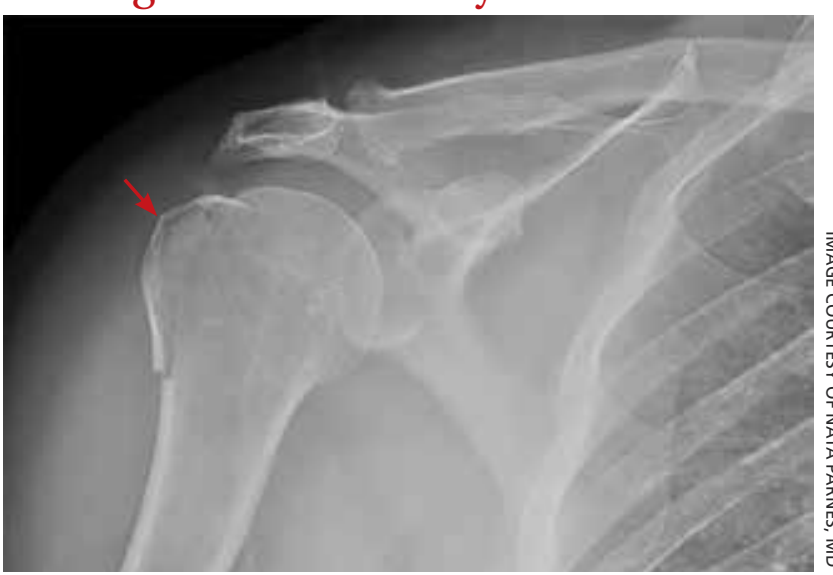

The fracture (arrow) is seen on a post-reduction, anteroposterior-view radiograph of the right shoulder.

\section{References}

1. Valencia Mora M, Ruiz Ibán MA, Heredia JD, et al Physical exam and evaluation of the unstable shoulder. Open Orthop J. 2017;11(suppl 6, M12):946-956. doi: 10.2174/1874325001711010946

2. Khiami F, Gérometta A, Loriaut P. Management of recent firsttime anterior shoulder dislocation. Orthop Traumatol Surg Res. 2015;101(1 suppl):S51-S57. doi: 10.1016/j.otsr.2014.06.027

3. Antonio GE, Griffith JF, Yu AB, et al. First-time shoulder dislocation: high prevalence of labral injury and age-related differences revealed by MR arthrography. J Magn Reson Imaging. 2007;26:983-991. doi: 10.1002/jmri.21092

4. Carrazzone OL, Tamaoki MJS, Ambra LFM, et al. Prevalence of lesions associated with traumatic recurrent shoulder dislocation. Rev Bras Ortop. 2015;46:281-287. doi: 10.1016/ S2255-4971(15)30196-8

5. Mahaffey BL, Smith PA. Shoulder instability in young athletes. Am Fam Physician. 1999;59:2773-2787.

6. Amar E, Maman E, Khashan M, et al. Milch versus Stimson technique for nonsedated reduction of anterior shoulder dislocation: a prospective randomized trial and analysis of factors affecting success. J Shoulder Elbow Surg. 2012;21:1443-1449. doi: 10.1016/ j.jse.2012.01.004

7. Jain NB, Wilcox RB 3rd, Katz JN, et al. Clinical examination of the rotator cuff. PM R. 2013;5:45-56. doi: 10.1016/ j.pmrj.2012.08.019 


\section{CONTINUED FROM PAGE 375}

8. Lizzio VA, Meta F, Fidai M, et al. Clinical evaluation and physical exam findings in patients with anterior shoulder instability. Curr Rev Musculoskelet Med. 2017;10:434-441. doi: 10.1007/ s12178-017-9434-3

9. Farber AJ, Castillo R, Clough M, et al. Clinical assessment of three common tests for traumatic anterior shoulder instability. J Bone Joint Surg Am. 2006;88:1467-1474. doi: 10.2106/JBJS.E.00594

10. Robinson CM, Shur N, Sharpe T, et al. Injuries associated with traumatic anterior glenohumeral dislocations. J Bone Joint Surg Am. 2012;94:18-26. doi: 10.2106/JBJS.J.01795

11. de Laat EA, Visser CP, Coene LN, et al. Nerve lesions in primary shoulder dislocations and humeral neck fractures. A prospective clinical and EMG study. J Bone Joint Surg Br. 1994;76: 381-383.

12. Avis D, Power D. Axillary nerve injury associated with glenohumeral dislocation: a review and algorithm for management EFORT Open Rev. 2018;3:70-77. doi: 10.1302/2058-5241.3.170003

13. Drury JK, Scullion JE. Vascular complications of anterior dislocation of the shoulder. Br J Surg. 1980;67:579-581. doi: 10.1002/ bjs. 1800670817

14. Lafuente JLA, Marco SM, Pequerul JMG. Controversies in the management of the first time shoulder dislocation. Open Orthop J. 2017;11:1001-1010. doi: 10.2174/1874325001711011001

15. te Slaa RL, Brand R, Marti RK. A prospective arthroscopic study of acute first-time anterior shoulder dislocation in the young: a five-year follow-up study. J Shoulder Elbow Surg. 2003;12 529-534. doi: 10.1016/s1058-2746(03)00218-0

16. Kavaja L, Lähdeoja T, Malmivaara A, et al. Treatment after traumatic shoulder dislocation: a systematic review with a network meta-analysis. Br J Sports Med. 2018;52:1498-1506. doi: 10.1136/ bjsports-2017-098539

17. Krych AJ, Sousa PL, King AH, et al. The effect of cartilage injury after arthroscopic stabilization for shoulder instability. Orthopedics. 2015;38:e965-e969. doi: 10.3928/01477447-20151020-03

18. Polyzois I, Dattani R, Gupta R, et al. Traumatic first time shoulder dislocation: surgery vs non-operative treatment. Arch Bone Jt Surg. 2016;4:104-108.

19. Maman E, Harris C, White L, et al. Outcome of nonoperative treatment of symptomatic rotator cuff tears monitored by magnetic resonance imaging. J Bone Joint Surg Am. 2009;91: 1898-1906. doi: 10.2106/JBJS.G.01335

20. Safran O, Schroeder J, Bloom R, et al. Natural history of nonoperatively treated symptomatic rotator cuff tears in patients 60 years old or younger. Am J Sports Med. 2011;39:710-714. doi: 10.1177/0363546510393944

21. Parnes N, Bartoszewski NR, Defranco MJ. Arthroscopic repair of full-thickness rotator cuff tears in active patients younger than 40 years: 2- to 5-year clinical outcomes. Orthopedics 2018;41: e52-e57. doi: 10.3928/01477447-20171114-02

22. Sofu H, Gürsu S, Koçkara N, et al. Recurrent anterior shoulder instability: review of the literature and current concepts. World J Clin Cases. 2014;2:676-682. doi: 10.12998/wjcc.v2.i11.676

23. Emond M, Le Sage N, Lavoie A, et al. Clinical factors predicting fractures associated with an anterior shoulder dislocation. Acad Emerg Med. 2004;11:853-858. doi: 10.1111/j.1553-2712.2004. tb00768.x

24. Parnes N, Jupiter JB. Fixed-angle locking plating of displaced proximal humerus fractures. Instr Course Lect. 2010;59:539-552. 